Authors have nothing to disclose with regard to commercial support.

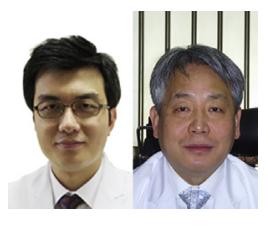

\section{SMALL RINGS AND EDGE-TO-EDGE TECHNIQUE ELEVATE TRANSMITRAL GRADIENTS IN MITRAL VALVE REPAIR}

\section{To the Editor:}

We read with great interest the article by $\mathrm{Ma}$ and colleagues $^{1}$ about elevated gradient after mitral valve repair and the effect of surgical technique and relevance of postoperative atrial fibrillation. Elevated transmitral gradient may cause not only delayed atrial fibrillation but also all other complications associated with pure mitral stenosis, such as left atrial enlargement, thromboembolism, secondary pulmonary hypertension, and delayed right heart failure. In the article of $\mathrm{Ma}$ and colleagues, ${ }^{1}$ the elevated pressure gradient after mitral annuloplasty was due to 2 main surgical problems: the use of small, complete, semirigid rings and the addition of edge-to-edge (E-to-E) repair after ring annuloplasty. $\mathrm{Ma}$ and colleagues ${ }^{1}$ used complete rings sized no larger than $32 \mathrm{~mm}$ (real ring area $<5.0 \mathrm{~cm}^{2}$ ) in more than $90 \%$ of patients who underwent mitral annuloplasty, with rings no larger than $30 \mathrm{~mm}$ (real ring area $<4.0 \mathrm{~cm}^{2}$ ) used in more than $40 \%$. After ring annuloplasty, the valve areas measured by echocardiography in the working heart are always significantly less $(50 \%-60 \%)$ than the actual ring areas. The use of such small, complete, semirigid rings may cause prosthesispatient mismatch (mean transmitral gradient $>5 \mathrm{~mm}$ $\mathrm{Hg}$ ). Mitral valve repair should not only eliminate valve regurgitation at systole but also make transmitral pressure gradient zero or low at diastole. In adults with an average height of $1.66 \mathrm{~m}$, the length of the anterior annulus (of the anterior leaflet) is $32 \pm 1.3 \mathrm{~mm} .^{2}$ For adults, the appropriate average ring size is $32 \mathrm{~mm}$ (ring area, $5.0 \mathrm{~cm}^{2}$ ). Small rings sized less than $30 \mathrm{~mm}$ may cause prosthesis-patient mismatch and high transmitral gradients. $^{3}$

\footnotetext{
The Editor welcomes submissions for possible publication in the Letters to the Editor section that consist of commentary on an article published in the Journal or other relevant issues. Authors should: • Include no more than 500 words of text, three authors, and five references. • Type with double-spacing. • See http://jtcs.ctsnetjournals.org/ misc/ifora.shtml for detailed submission instructions. • Submit the letter electronically via jtcvs.editorialmanager.com. Letters commenting on an article published in the JTCVS will be considered if they are received within 6 weeks of the time the article was published. Authors of the article being commented on will be given an opportunity of offer a timely response ( 2 weeks) to the letter. Authors of letters will be notified that the letter has been received. Unpublished letters cannot be returned.
}

Inappropriate combination of the E-to-E repair and ring annuloplasty may elevate valve gradient. Especially, the E-to-E procedure performed to remove residual valve regurgitation after annuloplasty with a ring of relatively small size increases the transmitral gradients. The E-to-E procedure is mostly used for Barlow disease with prolapse of redundant anterior leaflet. ${ }^{4}$ It prevents the elevation of the anterior leaflet above the level of the posterior leaflet, producing a double-orifice mitral valve. ${ }^{4} \mathrm{Ma}$ and colleagues $^{1}$ performed the E-to-E procedure with ring annuloplasty in $11 \%$ of patients $(n=44)$. They did not describe why the E-to-E procedure was performed, and they did not use rings of sufficient size for the E-to-E procedure. To obtain a total valve area of more than $2.5 \mathrm{~cm}^{2}$ with the addition of the E-to-E procedure, the mean size of the complete rings needs to be $36 \mathrm{~mm}$. The reduced valve area in ring annuloplasty is further reduced $30 \%$ to $50 \%$ by the E-to-E procedure. Moreover, the valve area measured in the working heart is even less than the actual ring area. When the E-to-E procedure is combined with annuloplasty that uses complete rings sized no larger than $32 \mathrm{~mm}$ (actual ring area $<5.0 \mathrm{~cm}^{2}$ ), the possibility of mitral stenosis being seen on postoperative echocardiography is very high. Some surgeons argue that, if each orifice is smaller than $2 \mathrm{~cm}$ in diameter, the E-to-E procedure should be abandoned. ${ }^{4}$ The E-to-E technique associated with ring annuloplasty should be performed carefully to prevent postoperative moderate or even severe mitral stenosis.

Nan Yeol Kim, MD

Jong Bum Choi, MD

Department of Thoracic and Cardiovascular Surgery Wonkwang University School of Medicine Hospital Iksan, Republic of Korea

\section{References}

1. Ma W, Shi W, Wu W, Ye W, Kong Y, Zhu D, et al. Elevated gradient after mitral valve repair: the effect of surgical technique and relevance of postoperative atrial fibrillation. J Thorac Cardiovasc Surg. 2019;157:921-7.e3.

2. Carpentier A, Adams DH, Filsoufi F. Surgical anatomy and physiology. In Carpentier A, Adams DH, Filsoufi F, eds. Carpentier's Reconstructive Valve Surgery. 1st ed. Maryland Heights, MO: Saunders Elsevier; 2010: 27-41.

3. Kawamoto N, Fujita T, Hata H, Shimahara Y, Sato S, Kobayashi J. Prosthesis-patient mismatch due to small ring annuloplasty in patients with degenerative mitral insufficiency. J Cardiol. 2016;68:141-7.

4. Loberman D, Pirundini PA, Byrne J, Cohn L. Mitral valve repair. In: Cohn LH, Adams DH, eds. Cardiac Surgery in the Adult. 5th ed. New York: McGraw-Hill Education; 2018:797-816.

5. De Bonis M, Lapenna E, Lorusso R, Buzzatti N, Gelsomino S, Taramasso M, et al. Very long-term results (up to 17 years) with the double-orifice mitral valve repair combined with ring annuloplasty for degenerative mitral regurgitation. $J$ Thorac Cardiovasc Surg. 2012;144:1019-24. Erratum in: J Thorac Cardiovasc Surg. 2013;145:617.

https://doi.org/10.1016/j.jtcvs.2019.05.052 